\title{
Optimization of Malaxation Process using Major Aroma Compounds in Virgin Olive Oil
}

\author{
Serife Cevik ${ }^{1}$, Gulcan Ozkan ${ }^{*}$, Mustafa Kıralan ${ }^{2}$. \\ ${ }^{1}$ Suleyman Demirel University, Faculty of Engineering, Department of Food Engineering, Isparta, TURKEY; ${ }^{2} A b a n t$ \\ IzzetBaysal University, Faculty of Engineering and Architecture,Department of Food Engineering, Bolu, TURKEY.
}

\begin{abstract}
Optimization of major aroma compounds in olive oils produced from fruits at three maturity stages wasstudied. A central composite design was used for the optimization of malaxation conditions of temperature and times, each at five levels with 13 runs including five central points. The responses of interest were trans-2-hexenal and hexanal, which were investigated and their contents were optimized. A full quadratic second order regression model including the linear, quadratic, and two factor interaction effects was proposed to explain the variation in the contents of target compounds depending on the malaxation conditions. Adequacies of models were evaluated by checking regression coefficients for each model. Models were found to work with high success for trans-2-hexenal prediction for oils from fruits at both purple and black stages, whereas the model for hexanalwas only in black stage oil. Their regression coefficients were higher than 0.86. Influences of time and temperature for the malaxation process were found to be significant for the transition of major aroma compounds from the fruit matrix to olive oil. The optimum conditions of temperature and time pairs to maximize trans-2-hexenal and hexanal was found to be $23^{\circ} \mathrm{C} / 31$ minutes for black olive and to maximize only trans-2-hexenal was also $29^{\circ} \mathrm{C} / 41$ minutes for purple olive.
\end{abstract}

Key words:hexanal, trans-2-hexenal, maturity, response surface method (RSM)

\footnotetext{
*Authors for correspondence: gulcanozkan@sdu.edu.tr
} 


\section{INTRODUCTION}

Virgin olive oil (VOO) is the primary part of Mediterranean diet and is produced from the olive fruit by means of mechanical or physical methods. VOO comprise mainly triglycerides and a wide range of minor compounds including minerals, phenolics, sterols, tocopherols, phospholipids, hydrocarbons and volatile compounds(1-3). One of the important minor compounds that are responsible for sensorial acceptability is volatile compounds, which make olive oil valuable among vegetable oils.

The volatile compounds give positive attributes to VOO, so these compounds are correlated with the quality of VOO. These compounds occur via a pathway involving the enzyme lipoxygenase (LOX), which are mainly produced by the oxidation of linoleic and linolenic fatty acids (4).

The major volatile compounds are the $\mathrm{C}_{6}$ and $\mathrm{C}_{5}$ compounds of VOO. These compounds become positive contributors to VOOs and are generally detected in high quality olive oils (5). Hexanal and trans-2-hexenal are produced by linoleic and linolenic fatty acids, respectively, in the LOX pathway (6). trans-2-Hexenal is the main volatile compound in high quality olive oils $(7,8)$ and this compound decreases with ripening in olive oils (9). In contrast to trans-2-hexenal, hexanal content increases in olive oils as the olive fruit ripens (10).

Besides ripening, olive oil processing steps including crushing, malaxation and separation of phases by centrifugation or pressingaffect aldehydes,giving positive sensory characteristics to olive oil (11). The malaxation, in another word, kneading is in fact much more than a simple physical separation step; a complex bioprocess takes place, which substantially designates final product quality and composition(12).Time and temperature variables in a malaxation are the key factors of this step, which produce good quality olive oils (13). The temperature increase enhances the hexanal concentration in olive oils. On the contrary, trans-2-hexenal content decreases with malaxation temperature (14). Effect of malaxation time on volatile compounds has less than temperature. A decreasing trend in trans-2-hexenal and an increasing trend in hexanalwas observed withprolonged time (15).

Several studies have shown that malaxation conditions aresignificantto obtain a good quality olive oil. These studies have emphasized that a wide range of malaxation temperatures and times may be applied in production of olive oil with high quality due to volatile compounds (16-18). In these works, the volatile oil composition of Italian and Spanish olive oils from same harvest period was assessed using these oils as material. However, these studies do not include the mathematical expression of the effects of process conditions on aroma profile. In modelling studies, mathematical equations are used to express the variation in the target value as a function of process factors and these models are helpful for process and product design, the prediction of target value without any experiment. Thus, the current study has been designed to produce a mathematical expression to explain the change of main two aroma compounds in olive oil depending on the malaxation step. As the best knowledge of authors, this study was the first research work focusing on the mathematical modelling of aroma compound transition depending on process conditions. On the other hand, the current study considered olive fruits at three maturity stages and examined each group individually. The results of this study could be valuable for further scientific research and for olive oil manufacturers and provide significant contribution to this field.

Memecik olive cultivar (45\% of the total olive trees in Turkey) is planted in the Aegean area of Turkey. The oil yield is high and it can be characterized as very fruity with a unique aroma. Memecik oil is one of the economically important olive oils in Turkey $(19,20)$.

The objective of this study was to improve the technological knowledge regarding malaxation conditions of the Memecik VOO production using Response Surface Methodology. For this purpose, the malaxation temperature and time were selected as optimization factors for obtaining high quality VOO from the Memecik olive cultivar at three ripening stages. The volatile compounds, in particular, trans-2-hexenal and hexanal, which give green sensory attributes to Memecik oil, were used as dependent variables in optimization. The optimal operative conditions for malaxation of pastes of Memecikolive obtained from three different ripening periods could be applied in olive mills to enhance the organoleptic characteristics that are of great importance for engendering preference for consumers. 


\section{MATERIALS AND METHODS}

\section{Olive samples}

Memecik olives obtained from healthy fruits without any kind of infection or physical damage were handpicked from Yatağan county of Mugla province in Turkey, at three different stages: spotted, purple and black.

\section{Determination of Ripening Index (RI)}

Here, one hundred olive fruits were randomly taken to assess the level of maturity (ripening index or RI) based on evaluation of the olive skin and pulp colors (21). RI values range from 0 (100\% intense green skin) to 7 (100\% purple flesh and black skin). All RIs were determined in triplicate for each sample and the results were averaged. Ripening indexes of olives were found to be $3.01 \pm 0.38$ (Spotted stage), $4.76 \pm 0.43$ (Purple stage) and $6.63 \pm 0.49$ (Black stage).

\section{Extraction of Olive Oil}

The olive samples were mechanically processed under laboratory conditions by using a disk miller (HakkiUsta Machinery, Aydin, Turkey), malaxor (HakkiUsta Machinery, Aydin, Turkey) and a hydraulic press (Arikan Machinery, Isparta, Turkey). Leaves were removed and $1 \mathrm{~kg}$ of olive fruits with stones was crushed. Pressure was gradually increased up to $60 \mathrm{bar}$, and the system was kept for 5 min under that pressure. Separated oil was filtered through anhydrous sodium sulfate and cotton and stored in amber glass bottles at $4^{\circ} \mathrm{C}$ until analysis.

\section{Volatile Compounds Analysis}

SPME conditions:Two $\mathrm{g}$ of the sample was weighed into a $15 \mathrm{~mL}$ vial closed with a silicone septum. The sample was placed on a heating block at $45^{\circ} \mathrm{C}$ under magnetic stirring. After an equilibration time of $15 \mathrm{~min}, \mathrm{a}$ Carboxen/polydimethylsiloxane manual SPME fiber $(75 \mu \mathrm{m}$ Fused Silica, Supelco Ltd., Bellefonte, PA) was inserted into the vial and was maintained for $30 \mathrm{~min}$ at $45^{\circ} \mathrm{C}$ to extract volatile compounds from the olive oil. The fiber was then inserted into the injection port of the gas chromatograph for $5 \mathrm{~min}$ at $250^{\circ} \mathrm{C}$ for the desorption of flavor compounds.

GC/MS analysis: GC/MS analyses were performed on a Shimadzu GC-2010 gas chromatograph equipped with MS-QP2010 plus a mass spectrometer (Shimadzu Corporation, Kyoto,
Japan). Helium was the carrier gas at a rate of 1.6 $\mathrm{mL} / \mathrm{min}$ at $40^{\circ} \mathrm{C}$. An Rxi-5Sil MS (30 m x 0.25 $\mathrm{mm} \times 0.25 \mu \mathrm{m}$; Restek, Bellefonte, PA, USA) capillary column was used to separate volatile compounds. The column temperature was held at $40^{\circ} \mathrm{C}$ for $2 \mathrm{~min}$ and increased to $250^{\circ} \mathrm{C}$ at a rate of $4^{\circ} \mathrm{C} / \mathrm{min}$, and then held for $5 \mathrm{~min}$. The temperature of the ion source and the transfer line was $200^{\circ} \mathrm{C}$ and $250^{\circ} \mathrm{C}$, respectively. Electron impact mass spectra were recorded at ionization energy of $70 \mathrm{eV}$.

GC-MS analyses were accomplished in SCAN mode in the in the 40-300 amu mass range. Volatile compounds were identified by comparison of their retention indices and mass spectra with authentic standards, or, in some cases tentatively only by Wiley-NIST FFNSC mass spectra library search and Kováts retention indices (KI). KIs were calculated for each compound using a homologous series of C7-C30 n-alkanes and results were given as \% area.Hexanal and trans- 2-hexanal were identified using standard chemicals and the KIs were calculated as 801 and 850 , respectively.

\section{Experimental design}

A central composite design was selected for the optimization of malaxation conditions of temperature, time and rosemary addition, each at five levels with 13 runs including four central points. Optimization of the independent variables of temperature $\left(\mathrm{X}_{1}\right)$ and time $\left(\mathrm{X}_{2}\right)$ was carried out to achieve the best performance of hexanal $\left(Z_{1}\right)$, and trans-2-hexenal $\left(\mathrm{Z}_{2}\right)$; The range and levels of independent process variables with coded values and corresponding responses are given in Table 1. Response surface methodology (RSM) was used for optimization using Minitab Software (Minitab 16.1.1). A full quadratic second order regression model including the linear, quadratic and two factor interaction effects was used to predict the process (Eq. 1).

$$
Z=\beta_{0}+\sum_{i=1}^{2} \beta_{i} X_{i}+\sum_{i=1}^{2} \beta_{i i} X_{i}^{2}+\sum_{i=1}^{1} \sum_{j=i+1}^{2} \beta_{i j} X_{i} X_{j}
$$

where $\mathrm{Z}$ was the dependent variable, $\mathrm{X}$ was the independent variable, $\beta_{0}$ was the constant coefficient, $\beta_{i}$ was the linear coefficient (main 
effect), $\beta_{i i}$ was the quadratic coefficient, and $\beta_{i j}$ was the two factor interaction coefficient. Response surfaces of the predicted values obtained by the proposed models were plotted in the studied variable ranges by Sigma Plot Software (SPSS Inc., Chicago, IL, USA). Model adequacy was evaluated by considering the $\mathrm{R} 2$ value.

Table 1. Two-factor, five-level central composite design used for RSM

\begin{tabular}{ccccc}
\hline & \multicolumn{2}{c}{ Coded variables } & \multicolumn{2}{c}{ Uncoded variables } \\
\hline Run $^{\mathrm{a}}$ & $\mathrm{X} 1$ & $\mathrm{X} 2$ & Temperature $\left({ }^{\circ} \mathrm{C}\right)$ & Time (minute) \\
\hline 1 & 1 & -1 & 45 & 30 \\
2 & 1 & 1 & 45 & 60 \\
3 & 0 & 0 & 35 & 45 \\
4 & -1.41421 & 0 & 21 & 45 \\
5 & 0 & 0 & 35 & 45 \\
6 & 0 & 0 & 35 & 45 \\
7 & 0 & 0 & 35 & 45 \\
8 & 1.414214 & 0 & 49 & 45 \\
9 & -1 & 1 & 25 & 60 \\
10 & 0 & 1.414214 & 35 & 66 \\
11 & -1 & -1 & 25 & 30 \\
12 & 0 & 0 & 35 & 45 \\
13 & 0 & -1.41421 & 35 & 24 \\
\hline
\end{tabular}

${ }^{\mathrm{a}}$ Randomly distributed

\section{RESULTS AND DISCUSSION}

\section{The content of trans-2-hexenal and hexanal}

Two major aroma compounds for olive oil are trans-2-hexenal andhexanal, so the increases in the contents of these compounds are desired change in terms of consumers and manufacturers. In the current study, these compounds are in the group of desired aroma compounds of olive oil and the aim was to optimize the transition of these compounds to oil as a function of malaxation conditions. The experimental design prepared to produce olive oil from olive fruits at three maturity stages was given in Table 1, where malaxation temperature and time varied in each run. Produced olive oil samples from each run were analyzed and aroma compounds were determined. The contents of trans-2-hexenal and hexanalwere found to be varied depending on the malaxation conditions as well as the maturity stages of olive fruits used for oil production. The results were given in Table 2 . In general, an increase inhexanal and a decrease intrans-2-hexenal wereobserved from the spotted stage to the black stage of olive fruits. These results are similar to those reported byGómez-
Rico, Salvador (22), who found that the major volatile, trans-2-hexenal, decreased and hexanal increased with ripening in Spanish olive oils.trans2-Hexenal content of total volatile component was found be in the range of $48.45-78.64 \%$ for oil from spotted fruits, $32.11-74.52 \%$ for oil from purple fruits, and $26.73-65.03 \%$ for oil from black fruits. Other major aroma compounds of oil samples extracted from the fruits at spotted, purple, and black stages were found to be varied in the range of $7.66-9.87 \%, 5.63-11.89 \%$, and $8.00-$ $13.27 \%$, respectively.Similarly, the contents of hexanal and trans-2-hexenal of olive oil obtained Memecik cultivar at purple stage (RI: 4.13) were found as $17.18 \%$ and $56.94 \%$, repectively(2). The amount of major aroma compounds in VOO is known to differ in small extent as a result of difference in cultivar and maturity stages. The trans-2-hexenal of Tunisian oils was reported to be higher than $70 \%$ while that ofSpanish oils was found to be in the range of $37.3-64.0 \%(23,24)$. In these studies, hexanal content were determined as $3.1-11.3 \%$ in Tunisian oils and $2.1-7.4 \%$ in Spanish oils $(23,24)$. 
Table 2. The hexanal and trans-2-hexenal content of Memecik oils extracted from olive fruits at three maturity stages

\begin{tabular}{ccccccc}
\hline \multirow{2}{*}{ Runs $^{\mathrm{a}}$} & \multicolumn{3}{c}{ Hexanal $(\%$ area $)$} & \multicolumn{3}{c}{ trans-2-Hexenal $(\%$ area $)$} \\
\cline { 2 - 7 } & Spotted & Purple & Black & Spotted & Purple & Black \\
\hline 1 & 7.97 & 8.32 & 9.99 & 48.45 & 58.13 & 34.96 \\
3 & 8.15 & 7.44 & 10.32 & 49.98 & 49.38 & 32.64 \\
4 & 8.38 & 7.43 & 8.63 & 73.65 & 74.07 & 62.19 \\
5 & 9.87 & 9.88 & 12.28 & 67.16 & 73.35 & 57.87 \\
6 & 8.38 & 7.02 & 8.55 & 73.65 & 74.52 & 59.78 \\
7 & 8.05 & 8.25 & 9.25 & 73.85 & 73.56 & 61.82 \\
8 & 8.52 & 7.37 & 8.6 & 73.6 & 73.76 & 61.53 \\
9 & 8.83 & 8.13 & 11.13 & 66.54 & 32.11 & 26.73 \\
10 & 7.66 & 8.4 & 10.28 & 78.64 & 70.82 & 58.47 \\
11 & 8.37 & 6.71 & 9.57 & 70.55 & 62.37 & 38.08 \\
12 & 7.92 & 11.89 & 13.27 & 68.41 & 74.5 & 63.92 \\
13 & 8.59 & 7.08 & 8 & 73.48 & 74.42 & 65.03 \\
\hline
\end{tabular}

a, randomly distributed

\section{Model fitting}

Table 3 shows the analysis of variance of the regression parameters of the proposed full quadratic models, as a function of malaxation temperature and time. The models for hexanal and trans-2-hexenal at the spotted stage and that for hexanal at the purple stage were not significant ( $>>0.05)$. Remaining models presented showed high correlation coefficients for hexanal and trans2-hexenal, in other words the model developed for hexanal content of olive oil obtained from fruits at black stage and those for trans-2-hexenal content of oil samples extracted from fruits at purple and black stages were able to explain more than $85 \%$ of the variations in the content of these compounds depending on the malaxation conditions (Table 3 ).
The proposed mathematical expression, second order polynomial model included first, second and interaction terms, so it is possible to figure out the effects of these terms on trans-2-hexenal and hexanal transitions to olive oil. For the model produced for hexanal content of oil samples extracted from black fruits, it was seen that second order terms and their interaction were significant $(\mathrm{p}<0.05)$ (Table 3). As can be seen in Table 3, models developed for trans-2-hexenal content of oil samples from fruits at purple and black stages had significant first and second order terms of temperature and time $(\mathrm{p}<0.05)$, whereas interaction of these factors was not significant for both model ( $p>0.05)$.

Table 3. Regression coefficients of predicted models for the investigated responses of virgin olive oil extracted from fruits at three maturity stages

\begin{tabular}{|c|c|c|c|c|c|c|c|}
\hline & \multirow[b]{2}{*}{ Variable $^{\mathrm{a}}$} & \multicolumn{3}{|c|}{ Hexanal (\% area) } & \multicolumn{3}{|c|}{ trans-2-Hexenal (\% area) } \\
\hline & & Spotted & Purple & Black & Spotted & Purple & Black \\
\hline Intercept & $\beta 0$ & $14.780^{\mathrm{ns}}$ & $31.777 *$ & $50.653^{* * \pi k}$ & $-28.761^{\mathrm{ns}}$ & $-55.402^{* * * *}$ & $-52.188^{* \cdots *}$ \\
\hline Temperature & $\beta 1$ & $-0.254^{\mathrm{ns}}$ & $-1.205^{*}$ & $-1.497^{\mathrm{ns}}$ & $3.290^{\mathrm{ns}}$ & $6.588^{* * *}$ & $5.088^{* * * *}$ \\
\hline Time & $\beta 2$ & $-0.068^{\mathrm{ns}}$ & $-0.091^{\mathrm{ns}}$ & $-0.685^{\mathrm{ns}}$ & $2.320^{\mathrm{ns}}$ & $1.754^{*}$ & $2.417^{* *}$ \\
\hline Temp×Temp & $\beta 11$ & $-0.000^{\mathrm{ns}}$ & $0.013^{\mathrm{ns}}$ & $0.017^{* *}$ & $-0.060^{\mathrm{ns}}$ & $-0.099^{* * *}$ & $-0.094^{* * *}$ \\
\hline Timex Time & $\beta 22$ & $-0.001^{\mathrm{ns}}$ & $-0.001^{\mathrm{ns}}$ & $0.004^{*}$ & $-0.023^{\mathrm{ns}}$ & $-0.015^{*}$ & $-0.032^{* * *}$ \\
\hline Temp×Time & $\beta 12$ & $0.005^{\mathrm{ns}}$ & $0.006^{\mathrm{ns}}$ & $0.008^{*}$ & $0.003^{\mathrm{ns}}$ & $-0.017^{\mathrm{ns}}$ & $0.005^{\mathrm{ns}}$ \\
\hline \multicolumn{2}{|c|}{ Model } & ns & ns & $* *$ & ns & *** & **** \\
\hline \multicolumn{2}{|c|}{$\mathrm{R}^{2}$} & 37,78 & 56.61 & 86.52 & 70.29 & 94.97 & 97.22 \\
\hline
\end{tabular}


Effects of process conditions on transition of target aroma compounds to olive oil

Temperature and time are two parameters in malaxation step and they have significant effects on oil quality. In the current study, their effects on transition of trans-2-hexenal and hexanal to oil sample was investigated and malaxation process was optimized towards to maximum aroma transition. In this regard, the effects of temperature and time on trans-2-hexenal and hexanal transition was discussed in this section. In order to show these effects, Figure 1-3 were drawn for trans-2- hexenal content of olive oil obtained from purple and black stages and for hexanal content of olive oil obtained from black stage, since the models developed by regression analysis were just significant for trans-2-hexenal and hexanal transition in oil samples extracted from fruits at these maturity stages (Table 3 ). Figure 1 displayed the change in trans-2-hexenal content of olive oil extracted from purple stage fruits under the effects of temperature and time. As can be seen in Figure 1 , the increasing temperature in the studied range caused a decrease in trans-2-hexenal content.

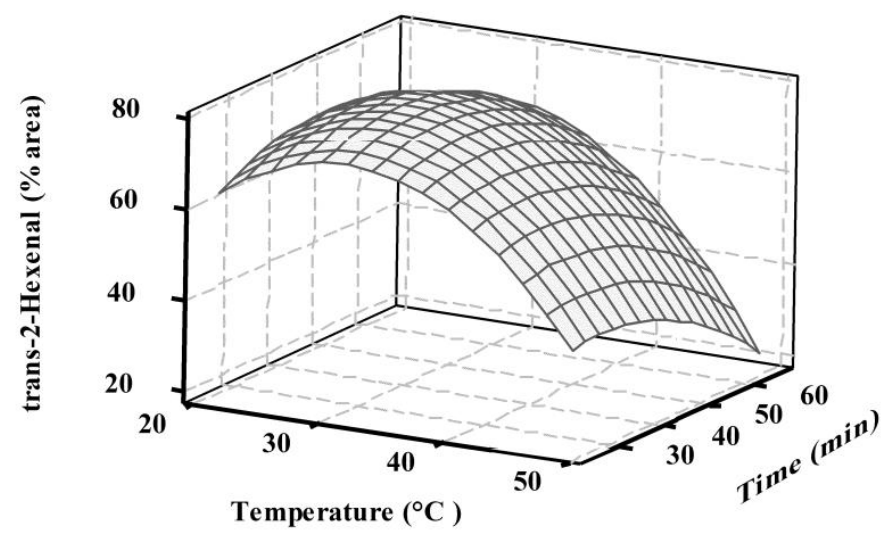

Figure 1. Influences of malaxation conditions on trans -2-hexenal of olive oil extracted from purple fruits 


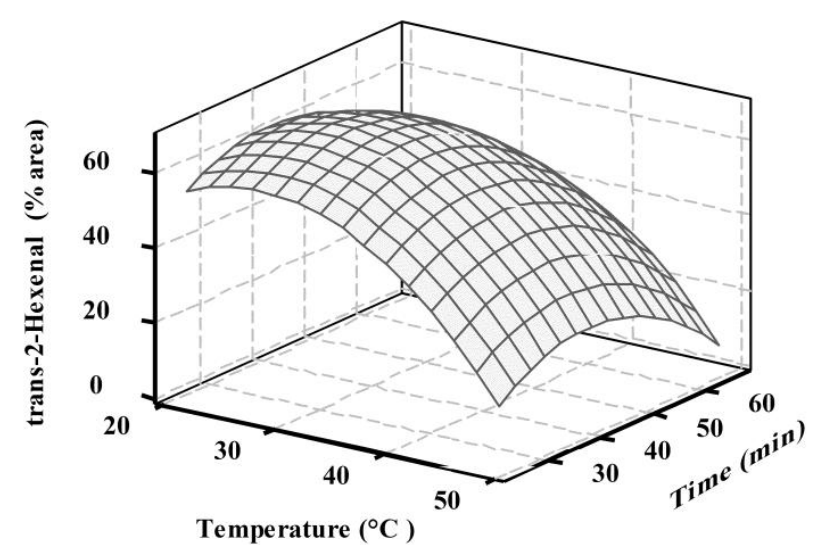

Figure 2. Influences of malaxation conditions on trans -2-hexenal of olive oil extracted from black fruits

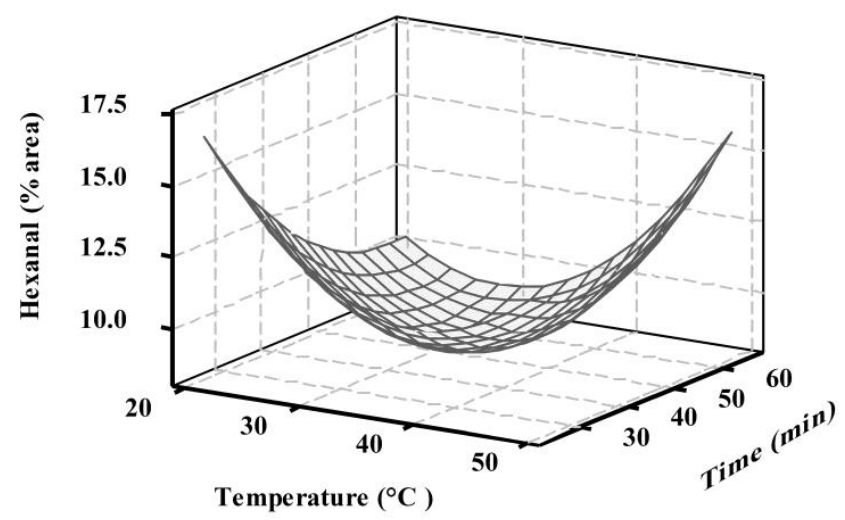

Figure 3. Influences of malaxation conditions on hexanal of olive oil extracted from black fruits

Time effect on trans-2-hexenal followed a curvature trend, so shifting in time from shortest to moderate process duration resulted in a slight increase in trans-2-hexenal, but greater time caused a decrease. As a result, the maximum for trans-2-hexenal content of oil sample obtained from purple stage fruits was seen around temperature range of $20-30^{\circ} \mathrm{C}$ and time range of 40-50 min (Fig 1). Figure 2 shows the temperature and time dependent change of trans-2-hexenal content in oil of black stage fruits. The general appearance of Figure 1 and 2 were identical, so it could be said that the influences of malaxation conditions on trans-2-hexenal transition to oil sample were similar. As a result, temperature and time ranges of $20-30^{\circ} \mathrm{C}$ and $40-50 \mathrm{~min}$ were the optimal process conditions for maximization of trans-2-hexenal in olive oil sample irrespective of 
fruit's maturity stage. These results are in agreement with those of Angerosa, Mostallino (25), who showed that trans-2-hexenal content increased with malaxation time in the oils from Coratina and Frantoio cultivars. The trans-2hexenal content of oils from olives treated with lower temperatures is consistent with the results of Angerosa, Mostallino (25), who observed that there was little change observed when the temperature increased from 25 to $35^{\circ} \mathrm{C}$.

Figure 3 showsthe effect of malaxation temperature and time on the hexanal content in oils from black fruits. The hexanal concentration decreased with temperature increase up to $40^{\circ} \mathrm{C}$ and after that level of temperature, an increase in this compound was observed. Malaxation time was another important parameter affecting the hexanal content of final olive oil. Variation of hexanal with time was shown in Figure 3. Especially at low temperature levels, a strong time effect was seen. An increase in time resulted in a sharp decrease in hexanal content, but this effect 'disappeared when the temperature was elevated. Moreover, at the highest studied level of temperature, longer malaxation produced an olive oil with higher hexanal content (Fig 3).

The decrease in concentration of hexanal with increasing temperature up to $30-40^{\circ} \mathrm{C}$ is consistent with the results of Tura, Prenzler (26)in which they investigated the effects of malaxation temperature at two levels $\left(25\right.$ and $\left.35^{\circ} \mathrm{C}\right)$ on transition of hexanal and result indicated the adverse effect on hexanal content in oil sample. A similar behavior was observed by Angerosa, Mostallino (25), who reported that malaxation conditions, especially time, act as a key role in the hexanal content of final olive oil. The content of this compound reached a higher value over prolonged times. A similar trend for hexanal with malaxation time was confirmed by $\mathrm{Di}$ Giovacchino, Costantini (11), who reported that the hexanal content of oils increases with a longer malaxation time $(90 \mathrm{~min})$. Additionally, Tura, Prenzler (26)in reported results that were consistent with the current one, where hexanal content was reported to increase when malaxation time was changed from 15 to $60 \mathrm{~min}$.

\section{Optimal process conditions for trans-2-hexenal and hexanalof olive oils}

The optimization of any process is significant in order to reach the desired goals. In the present study, the main goal is the optimization of malaxation conditions towards aim of olive oil extraction with strong aroma. For this purpose, transition of major aroma compounds in olive oils produced from fruits at three maturity stages (spotted, purple and black stage) was studied under the effects of malaxation conditions. To the best of our knowledge, there is no detailed information available about the influence of malaxation temperature and time on the transition of major aroma compounds to olive oil produced from Memecik cultivar. In this study, all oil samples produced according to experimental design were found to be within the limits established for high quality extra virgin olive oil under the levels classified in EU-regulations $(\mathrm{EEC} / 2568 / 91)$ (free acidity $\leq 0.8 \%$, peroxide value $\leq 20$ meq $_{2} / \mathrm{kg}$ oil).

The response surface methodology analysis indicated that only three models were statistically significant. According to analysis results, only the model produced for the hexanal content in oil sample extracted from black fruit was significant. For trans-2-hexenal content, the models developed for oils obtained from purple and black stages were significant. Thus the optimization of aroma content for olive oil extracted from purple fruits was performed by using the models developed for hexanal and trans-2-hexenal content together. However, optimal malaxation conditions were determined for oil sample obtained from black fruits just using the model developed for trans-2hexenal. The studied conditions were not optimized for oil sample extracted from spotted stage fruits, since no significant model was developed for aroma compounds in this oil. In light of these facts, the optimum conditions of temperature and time pairs to maximize trans-2hexenal was found to be $29^{\circ} \mathrm{C} / 41$ minutes for purple olive and to maximize trans-2-hexenal and hexanalwas $23^{\circ} \mathrm{C} / 31$ minutes for black oil.A similar trend can be seen from the results of Espínola, Moya (27), who reported that malaxation temperature and malaxation time could be selected in the range of $20-40^{\circ} \mathrm{C}$ and $64.8-82.7$ min in oils from different harvest times, according to models based on extraction yield and other quality factors.

\section{CONCLUSIONS}

Although low temperatures and short times are common recommendations for the malaxation 
process in olive oil production, there is still a need to determine the optimal malaxation conditions, so that the olive oil produced is of the highest quality. Desired volatile compounds are important indicators to distinguish good quality oils from poor ones. $\mathrm{C}_{6}$ volatile compounds which found in fresh and high quality oils, are responsible for positive attributes of olive oils (28). Among these $\mathrm{C}_{6}$ volatile compounds, hexanal and trans-2hexanal are the major desirable volatile compounds in fresh and high quality olive oils. trans-2-Hexenal is a major compound in the Tunisian (at least 70\%) and Spanish oils (37.3$64.0 \%$ ) and also hexanal is an important identified compound among $\mathrm{C}_{6}$ aldehydes and determined at $3.1-11.3 \%$ in Tunisian oils and $2.1-7.4 \%$ in Spanish oils $(23,24)$. In the light of these results major compounds could be a useful indicator to differentiate olive oils depending on malaxation conditions and also ripening index. In the literature, there is no informationabout the change in content of hexanal and trans-2-hexenal in Memecik oil depending on neither malaxation conditions nor maturity stage. Thus the current study produced valuable information in this extent. The models for hexanal and trans-2-hexenal content of olive oil extracted from fruits at three different maturity stages were developed and the process conditions were optimized for the aim of the highest content of target compounds. The optimal malaxation temperature and time for the production of Memecik oil are $\leq 29^{\circ} \mathrm{C}$ and $\leq 41$ $\mathrm{min}$, respectively. These results provide some idea of the optimal conditions for the production of Memecik oil which is rich in terms of trans-2hexenal and hexanal. In this respect, malaxation modelling could help to improve Memecik oil quality and standardize processing conditions to maintain the quality.

\section{ACKNOWLEDGMENT}

The present study was financially supported by SuleymanDemirel University Scientific Research Projects Coordination Unit (3281-YL2-12).

\section{REFERENCES}

1.Boskou D. Olive oil quality. In: Boskou D, editor. Olive Oil: Chemistry and Technology. Champaign, Illinois: AOCS Press; 1996. p. 101-20.

2.Dagdelen A, Ozkan G, Karasu S, Sagdic O. Differentiation of olive oils based on rheological and sensory characteristics obtained from six olive cultivars. Qual Assur Saf Crop Foods. 2016;8(3):41525.

3. Dağdelen A. Identifying Antioxidant and Antimicrobial Activities of the Phenolic Extracts and Mineral Contents of Virgin Olive Oils (Olea europaea L. cv. Edincik Su) from Different Regions in Turkey. J Chem. 2016;2016.

4. Kalua C, Allen M, Bedgood D, Bishop A, Prenzler P, Robards K. Olive oil volatile compounds, flavour development and quality: A critical review. Food Chem. 2007;100(1):273-86.

5. Angerosa F. Influence of volatile compounds on virgin olive oil quality evaluated by analytical approaches and sensor panels. Eur J Lipid Sci Technol. 2002;104(9-10):639-60.

6. Angerosa F, Basti C, Vito R. Virgin olive oil volatile compounds from lipoxygenase pathway and characterization of some Italian cultivars. Journal of Agricultural and Food Chemistry. 1999;47(3):836-9.

7. Vichi S, Pizzale L, Conte LS, Buxaderas S, LópezTamames E. Solid-phase microextraction in the analysis of virgin olive oil volatile fraction: characterization of virgin olive oils from two distinct geographical areas of northern Italy. J Agric Food Chem. 2003;51(22):6572-7.

8. Benincasa C, De Nino A, Lombardo N, Perri E, Sindona G, Tagarelli A. Assay of aroma active components of virgin olive oils from southern Italian regions by SPME-GC/ion trap mass spectrometry. J Agric Food Chem. 2003;51(3):733-41.

9. Gómez-Rico A, Fregapane G, Salvador MD. Effect of cultivar and ripening on minor components in Spanish olive fruits and their corresponding virgin olive oils. Food Research International. 2008;41(4):433-40.

10. Aparicio R, Morales MT. Characterization of olive ripeness by green aroma compounds of virgin olive oil. Journal of Agricultural and Food Chemistry. 1998;46(3):1116-22.

11. Di Giovacchino L, Costantini N, Ferrante M, Serraiocco A. Influence of malaxation time of olive paste on oil extraction yields and chemical and organoleptic characteristics of virgin olive oil obtained by a centrifugal decanter at water saving. Grasas y aceites. 2002;53(2):179-86.

12. Inarejos-García AM, Gómez-Rico A, Salvador MD, Fregapane G. Influence of malaxation conditions on virgin olive oil yield, overall quality and composition. Eur Food Res Technol. 2009;228(4):671-7.

13. Clodoveo ML. Malaxation: Influence on virgin olive oil quality. Past, present and future-An overview. Trends in Food Science \& Technology. 2012;25(1):13-23.

14. Ranalli A, Contento S, Schiavone C, Simone N. Malaxing temperature affects volatile and phenol composition as well as other analytical features of 
virgin olive oil. European Journal of Lipid Science and Technology. 2001;103(4):228-38.

15. Angerosa F, d'Alessandro N, Basti C, Vito R. Biogeneration of volatile compounds in virgin olive oil: their evolution in relation to malaxation time. Journal of Agricultural and Food Chemistry. 1998;46(8):2940-4.

16. Servili M, Selvaggini R, Taticchi A, Esposto S, Montedoro G. Volatile compounds and phenolic composition of virgin olive oil: optimization of temperature and time of exposure of olive pastes to air contact during the mechanical extraction process. Journal of Agricultural and Food Chemistry. 2003;51(27):7980-8.

17. Kalua CM, Bedgood DR, Bishop AG, Prenzler PD. Changes in volatile and phenolic compounds with malaxation time and temperature during virgin olive oil production. J Agric Food Chem. 2006;54(20):7641-51.

18. Gómez-Rico A, Inarejos-García AM, Salvador MD, Fregapane G. Effect of malaxation conditions on phenol and volatile profiles in olive paste and the corresponding virgin olive oils (Olea europaea L. Cv. Cornicabra). J Agric Food Chem. 2009;57(9):358795.

19. Gümusay B, Ozilbey U, Ertem G, Oktar A. Studies on the susceptibility of some important table and oil olive cultivars of Aegean Region to olive fly (Dacus oleae Gmel.) in Turkey. Acta Hortic. 1990;286:359-61.

20. Kesen S, Kelebek H, Sen K, Ulas M, Selli S. GC-MS-olfactometric characterization of the key aroma compounds in Turkish olive oils by application of the aroma extract dilution analysis. Food Res Int. 2013;54(2):1987-94.

21. Uceda M, Hermoso M. Quality olive oil [La calidad del aceite de oliva]. In: Barranco D, Fernández-Escobar R, Rallo L, editors. Olive cultivation [El cultivo del olivo]. Sevilla and Madrid: Junta de Andalucia and Ediciones Mundi-Prensa; 1998. p. 547-72.

22. Gómez-Rico A, Salvador MD, La Greca M, Fregapane G. Phenolic and volatile compounds of extra virgin olive oil (Olea europaea L. Cv. Cornicabra) with regard to fruit ripening and irrigation management. J Agric Food Chem. 2006;54(19):7130-6.

23. Cavalli J-F, Fernandez X, Lizzani-Cuvelier L, Loiseau A-M. Characterization of volatile compounds of French and Spanish virgin olive oils by HS-SPME: Identification of quality-freshness markers. Food Chemistry. 2004;88(1):151-7.

24. Haddada FM, Manai H, Daoud D, Fernandez X, Lizzani-Cuvelier L, Zarrouk M. Profiles of volatile compounds from some monovarietal Tunisian virgin olive oils. Comparison with French PDO. Food Chemistry. 2007;103(2):467-76.
25. Angerosa F, Mostallino R, Basti C, Vito R. Influence of malaxation temperature and time on the quality of virgin olive oils. Food Chemistry. 2001;72(1):19-28.

26. Tura D, Prenzler PD, Bedgood DR, Antolovich M, Robards K. Varietal and processing effects on the volatile profile of Australian olive oils. Food Chemistry. 2004;84(3):341-9.

27. Espínola F, Moya M, Fernández DG, Castro E. Modelling of virgin olive oil extraction using response surface methodology. International Journal of Food Science \& Technology. 2011;46(12):257683.

28. Morales M, Aparicio R. Effect of extraction conditions on sensory quality of virgin olive oil. J Am Oil Chem Soc. 1999;76(3):295-300.

Received: January 15, 2016 Accepted: May11, 2016 